Vol 5 No 1 Tahun 2020 (61-68)
$\frac{\text { JTttp://eiournal.upi.edu/index.php/JTIKOR }}{\text { doi: } 10.17509 / \text { itikor.v5i1.24168 }}$

\title{
Pengaruh Kinematics Feedback dan Slow Motion Feedback Berbasis Aplikasi Android Terhadap Penguasaan Teknik Dasar Bola Basket Dihubungkan dengan Tingkat Kecerdasan
}

\author{
Putri Kamila Nur Laila ${ }^{\bowtie}$, Agus Rusdiana, dan Yudy Hendrayana \\ Pendidikan Olahraga, Sekolah Pascasarjana Universitas Pendidikan Indonesia, Bandung, \\ Indonesia
}

\section{Info Artikel}

Kata Kunci:

Kinematic Feedback, Slow

Motion Feedback, Tingkat

Kecerdasan, Penguasaan Bola

Basket

\section{Keywords:}

Kinematic Feedback, Slow Motion Feedback, Level of intellegence, mastering the basic techniques of basketball

Alamat korespondensi:
Gg.cempaka 100b geger kalong
girang, Bandung
E-mail:
putrikamilanurlaila@gmail.com

\begin{abstract}
Abstrak
Perencanaan dalam pendidikan jasmani adalah kompetensi penting bagi guru pra-jabatan yang sedang berkembang di seluruh program universitas. Dapat diketahui bahwa umpan balik membantu guru untuk menyadari tindakan mereka dalam mengajar. Efektivitas dalam kelas pendidikan jasmani lebih baik dapat dicapai dengan peningkatan penggunaan waktu dan orientasi intruksi yang benar oleh guru(Viciana, Fdez-revelles, Zabala, \& Requ, 2013). Penelitian ini bertujuan untuk mengetahui pengaruh umpan balik melalui aplikasi android dengan media pembelajaran video kinematic dan video slow motion, dan untuk mengetahui adakah hubungan tingkat kecerdasan dengan penguasaan teknik dasar bola basket. Pengambilan sampel menggunakan teknik purposive sampling pada siswa SMP Nasional Bandung sebanyak 72 orang. Berdasarkan hasil analisis data menunjukkan bahwa terdapat pengaruh yang signifikan atas pemberian umpan balik yang diberikan dengan masing-masing kelompok melalui media pembelajaran video kinematic sebesar 35\% dan video slow motion sebesar 31\%. Hasil penelitian dari korelasi antara tingkat kecerdasan dengan keterampilan siswa dengan hasil 0,154 yang dimana nilai sig. $>0,05$ diperoleh informasi bahwa tidak terdapat hubungan.
\end{abstract}




\section{PENDAHULUAN}

Permainan bola basket adalah permainan bola besar yang dimainkan dengan cara di oper ke sesama teman seregunya, di pantulkan maupun di gelindingkan, dan dimainkan dengan lima orang pemain dari dua regu yang berlawanan serta bertujuan untuk memasukkan bola sebanyak-banyaknya ke keranjang lawan serta mencegah kemasukan di keranjangnya sendiri. Olahraga bola basket juga diberikan pada bidang pendidikan khususnya pada pelajaran jasmani di sekolah. Keterampilan perseorangan seperti dribbling, passing dan shotting serta kerja tim untuk menyerang atau bertahan adalah prasayarat agar berhasil dalam memainkan olahraga ini. Seorang pemain yang terus menerus berlatih baik secara fisik maupun teknik, tetap tidak memberikan kesempatan melatih proses berfikir akan berakibat kegiatan yang bersifat intelektual menjadi tidak berkembang. Perencanaan dalam pendidikan jasmani adalah kompetensi penting bagi guru pra-jabatan yang sedang berkembang di seluruh program universitas. Dapat diketahui bahwa umpan balik membantu guru untuk menyadari tindakan mereka dalam mengajar.

Efektivitas dalam kelas pendidikan jasmani lebih baik dapat dicapai dengan peningkatan penggunaan waktu dan orientasi intruksi yang benar oleh guru (Viciana et al., 2013). Namun, dalam konteks pengajaran pendidikan jasmani, di mana waktu adalah komoditas berharga. Umpan balik berbasis video sangat tidak biasa karena waktu yang dibutuhkan untuk mendirikan beberapa peralatan (Chaudhury, Garg, \& Sharma, 2003). Feedback atau yang disebut umpan balik didefinisikan sebagai informasi terkait respons apa pun yang diterima baik selama atau setelah produksi keterampilan gerakan. Ada dua kategori umpan balik yang luas. Ini disebut umpan balik indera dan umpan balik tambahan (Principles, Fifth, Richard, \& Timothy, n.d.). Umpan balik sangat penting untuk pembelajaran yang efektif. Bahkan, setelah jumlah waktu yang dihabiskan dalam latihan mungkin merupakan faktor terpenting dalam seberapa baik seseorang pada awalnya mempelajari keterampilan baru. jenis umpan balik yang dapat disediakan dan metode untuk memberikan umpan balik yang paling efektif kepada peserta didik (Edwards, n.d.). Pengetahuan tentang kinerja atau Konwledge of Performance (KP) atau umpan balik kinematik mengacu pada informasi yang diberikan kepada pemain yang menunjukkan kualitas atau pola pergerakan (Olen, 2012). Setiap percobaan tes umpan balik kinematik dapat mempengaruhi pembelajaran dengan cara Knowledge of Result (Young \& Schmidt, 1992).

Umpan balik kinematic dan slow motion berasal dari umpan balik ekstrinsik atau tambahan. Kinematic merupakan satu ilmu fisika dari mekanika klasik dimana membahas pergerakan sebuah benda dengan kondisi tidak mempersoalkan penyebab dari pergerakan itu. Kinematic feedback mengacu pada informasi pola pergerakan termasuk seperti perpindahan, kecepatan atau gerak sendi. Adapun umpan balik gerak lambat atau dapat disebut dengan slow motion feedback menggunakan ruang desain. Jelas bahwa umpan balik gerak lambat tidak masuk akal untuk tugas yang berjalan lama maksudnya ketika durasinya dari suatu tindakan cukup lama sehingga pengguna memiliki kesempatan untuk melakukan gerakan (Vermeulen, Luyten, Coninx, \& Marquardt, n.d.). Seorang pemain yang terus menerus berlatih baik secara fisik maupun teknik, tetap tidak memberikan kesempatan melatih proses berfikir akan berakibat kegiatan yang bersifat intelektual menjadi tidak berkembang. Intelegensi juga dapat diartikan sebagai kemampuan yang dibawa sejak lahir, yang memungkinkan seseorang berbuat sesuatu dengan cara tertentu. Kebetuhan siswa terkait dengan tingkat psikososial siswa. Guru harus berhati-hati saat memberikan umpan balik untuk perbaikan atau koreksi atas kekeliruan yang dilakukan siswa. Teori Vygotsky tentang zona perkembangan proksimal adalah bahwa peran guru sebagai mediator pada kegiatan belajar siswa saat mereka saling berbagi pengetahuan melalui interaksi social berlangsung selama pembelajaran.

Melalui interaksi social siswa dapat umpan balik yang baik dan efektif terhadap 
penguasaan gerak dalam materi. Dalam penalaran atau pemahaman yang ia dapatkan dari umpan balik sebuah materi yang baru merupakan skema dari kecerdasan seseorang. Tingkat kecerdasan sangat mempengaruhi pemain dalam menerima, mempelajari dan memahami materi-materi yang diberikan. Semakin cerdas seorang siswa maka semakin mudah pula siswa dalam menerima dan memahami materi yang diberikan. Dengan memiliki kecerdasan atau $I Q$ yang baik maka siswa akan lebih cepat mengarahlan pola-pola arah boa yang lebih efektif.

Penggunaan teknologi digital dalam pendidikan jasmani berbeda secara fundamental dari penggunaannya dalam mata pelajaran sekolah lainnya. Hal ini karena proses pembelajaran dalam ranah psikomotor dapat diamati secara langsung dan publik (mis., dapat dilihat oleh teman dan guru). Dengan demikian teknologi digital dapat dimanfaatkan untuk membantu menghadirkan pembelajaran proses untuk hidup bagi pelajar (Casey \& Jones, 2011). Bagaimana teknologi digital dapat digunakan untuk mengembangkan kesadaran siswa akan taktik dalam permainan berbasis pelajaran. Misalnya, guru dapat menggunakan umpan balik berbasis video untuk memperkaya cara mereka mengajarkan pedagogi game.

Secara khusus, analisis rekaman video yang menunjukkan aspek taktis permainan dapat membantu tingkat permainan taktis yang lebih tinggi dan partisipasi yang lebih besar oleh siswa (Harvey \& Gittins, 2014). Selain itu, pembelajaran taktis siswa dapat difasilitasi dengan memberi mereka tugas analisis video sebagai pekerjaan rumah. Satu peringatan adalah bahwa penugasan semacam itu memerlukan lebih banyak waktu (mis., pengeditan video) untuk mempersiapkan tugas. Ketika guru mengenali kemudahan penggunaan dan bagaimana ini benar-benar bermanfaat bagi pembelajaran siswa, itu akan menjadi lebih kemungkinan bahwa mereka akan ingin menggunakan teknologi baru (Tannehill, van der Mars, \& MacPhail, 2015).

Dalam mempelajari penggunaan teknologi seperti itu seharusnya tidak hanya focus bagaimana kombinasi dari inovasi teknologi dan pedagogis ini sebenarnya dapat mendorong siswa belajar dalam konteks permainan; mereka juga harus fokus pada pengembangan pemahaman yang lebih besar penggunaan teknologi guru dalam pendidikan jasmani sebagai pusat area inkuiri dalam area ini (Mumtaz, 2000). Seperti halnya dengan banyak pilihan lain yang harus diambil guru relatif terhadap strategi pengajaran, setiap orang harus memutuskan apakah dibenarkan dan bermanfaat untuk menggunakan teknologi digital yang disajikan sini Inti dari pendidikan jasmani tetap untuk mengembangkan keterampilan gerak paling utama dan terpenting. Dalam konteks itu, guru biasanya menginstruksikan melalui arahan dan instruksi lisan (mis., konfirmasi, umpan balik, tanya jawab). Penggunaan gambar video yang ditandai segera dapat diakses membantu siswa ketika mereka menghadapi ketika sendiri bertindak dalam konteks game langsung. Sebagai contoh guru dapat menggunakan umpan balik berbasis video untuk memperkaya cara mereka mengajar permainan pedagogi.

Secara khusus, analisis rekaman video yang menunjukkan aspek taktis dari permainan mungkin mendorong tingkat yang lebih tinggi dari bermain taktis wawasan dan partisipasi yang lebih besar oleh siswa (Koekoek, van der Mars, van der Kamp, Walinga, \& van Hilvoorde, 2018). Dalam aktivitas pembelajaran penjas, perilaku guru menghargai siswa dan ia berkomunikasi secara efektif diwujudkan dalam prsoses pemberian umpan balik (feedback). Umpan balik sangat penting untuk pembelajaran yang efektif. Berdasarkan pengamatan di lapangan bahwa proses pembelajaran pendidikan jasmani dalam materi bola basket sebagian siswa cenderung kurang aktif melakukan gerakan teknik dasar terhadap materi yang diberikan, kurangnya pemahaman materi dan akan berdampak pada kemampuan siswa untuk menjalankan instruksi kurang paham. Kebanyakan siswa malas untuk membaca apalagi dalam proses pembelajaran pendidikan jasmani yang dimana siswa ingin bebas beraktivitas atau bebas melakukan 
gerakan agar tidak cenderung diam untuk melakukan olahraga. Peneliti ingin memberikan umpan balik kepada siswa melalui aplikasi android dengan media pembelajaran video kinematics dan slow motion agar siswa dapat memahami apa yang telah disampaikan oleh guru agar siswa juga tidak bosan mengikuti proses pembelajaran pendidikan jasmani. Peneliti ingin memberikan inovasi baru agar proses pembelajaran dapat berjalan dengan efesien dan efektif. Untuk tujuan ini, peneliti mengharapkan adanya pengaruh umpan balik yang diberikan untuk pemahaman penguasaan teknik dasar bola basket melalui aplikasi android dan ingin mengetahui adakah hubungan antara tingkat kecerdasan dengan keterampilan penguasaan teknik dasar pada bola basket.

\section{METODE}

\section{Partisipan dan Desain Penelitian}

Populasi dalam penelitian ini adalah siswa SMP Nasonal Bandung. Pengambilan sampel menggunakan teknik purposive sampling, yaitu teknik penentuan sampel berdasarkan pertimbangan tertentu pada siswa sebanyak 72 orang. Peneliti menggunakan siswa kelas VIII A dan E. Penelitian ini menggunakan metode eksperimen dapat diartikan sebagai metode penelitian yang digunakan untuk mencari pengaruh perlakuan tertentu terhadap yang lain dalam kondisi yang terkendalikan. Peneliti menggunakan desain factorial design $2 \times 2$. Variabel dapat digolongkan menjadi variable bebas, variable terikat dan variable moderator. Variable dalam penelitian ini adalah variable terikat yaitu umpan balik kinematic dan slow motion, variable bebas yaitu tingkat kecerdasan, dan variable moderator penguasaan teknik dasar bola basket. Untuk memperjelas gambaran mengenai desain yang diajukan oleh peneliti dapat dilihat pada tabel 1 berikut.

Tabel 1. Desain Penelitian

\begin{tabular}{|c|c|c|}
\hline Feedback & $\begin{array}{c}\text { Kinematic Feedback } \\
\left(\mathrm{X}_{1}\right)\end{array}$ & $\begin{array}{c}\text { Slow Motion Feedback } \\
\left(\mathrm{X}_{2}\right)\end{array}$ \\
\hline $\begin{array}{c}\text { Kecerdasan Intelektual } \\
\text { (IQ) } \\
\text { Tinggi }\left(\mathrm{Y}_{1}\right)\end{array}$ & $\mathrm{X}_{1} \mathrm{Y}_{1}$ & $\mathrm{X}_{2} \mathrm{Y}_{1}$ \\
\hline $\begin{array}{c}\text { Kecerdasan Intelektual } \\
\text { (IQ) } \\
\text { Rendah }\left(\mathrm{Y}_{2}\right)\end{array}$ & $\mathrm{X}_{1} \mathrm{Y}_{2}$ & $\mathrm{X}_{2} \mathrm{Y}_{2}$ \\
\hline \multicolumn{3}{|c|}{$\begin{array}{c}\text { Penguasaan Gerak Bola } \\
\text { Basket }\end{array}$} \\
\hline
\end{tabular}

\section{Instrumen}

Siswa tes IQ terlebih dahulu untuk mengetahui kategori IQ tinggi, sedang dan rendah. Peneliti bekerja sama dengan Lab.Psikologi dan Bimbingan Konseling di FIP UPI. Instrumen yang digunakan oleh peneliti ini menggunakan alat pengumpulan data dengan melakukan pre-test dan post-test. Setelah terdapat beberapa kelompok dari tes IQ siswa terbagi lagi menjadi 2 kelompok yaitu kelompok Kinematic dan Slow Motion dengan melakukan tes teknik dasar dribbling, passing dan shooting masingmasing melakukan tes 5 kali percobaan.

Intrumen yang digunakan untuk umpan balik kinematics dan slow motion berupa media pembelajaran melalui video. Pada video kinematic merupakan suatu hasil akhir dari tindakan dengan sudut, kecepatan dan tinggi dasar bola didasarkan pada mekanis gerak dan ilustrasi dalam proses tindakan selama pelaksanaan. Proses perlakuan yang akan diberikan sebagaimana siswa mengamati video gerakan kinematc teknik dasar bolaa basket yang dimana video tersebut merupakan rangkaian gerakan dengan gerak titik dan sudut per gerakan yang dilakukan seseorang dalam video.

Gambaran dari slow motion feedback yang merupakan gerak lambat atau yang dimaksud dengan durasi dari suatu tindakan yang cukup lama sehingga siswa memiliki kesempatan untuk mencoba dengan step by step. Proses perlakuan yang akan diberikan sebagaimana siswa mengamati video gerakan slow motion teknik dasar bolaa basket yang dimana video tersebut merupakan video tahapan teknik dasar yang berdurasi lambat.

\section{Prosedur}

Tes yang dilakukan peneliti pada siswa sesuai dengan kategori IQ yang sebelumnya di tes terlebih dahulu untuk mengetahui tingkat kecerdasan pada siswa dengan hasil yang dikategorikan tinggi, sedang dan rendah. Perlakuan yang diberikan kepada siswa yaitu siswa melihat video melalui aplikasi Physical Education (PE) yang telah dibuat oleh peneliti. Aplikasi tersebut yang didalamnya terdapat pembelajaran PJOK dengan fitur materi, game, 
video pembelajaran, dan kuis berbagai cabang olahraga. Siswa mengamati video kinematic dan slow motion video yang dimana video tersebut merupakan video tahapan teknik dasar bola basket. Siswa terbagi rata sesuai kelompok kategori IQ. Setiap individu melakukan pre-test dan post-test gerakan dribbling, passing, dan shooting. Selain itu ada sesi tanya jawab sebelum pengumpulan data, dimana para siswa mampu menjelaskan keberhasilan dan kegagalan sehubungan dengan tugas. Setelah siswa mengamati video tersebut siswa di harapkan mencoba dengan apa yang telah di amati.

\section{Analisis Data}

Untuk membantu analisis tersebut penulis memanfaatkan penggunaan perhitungan statistika dengan menggunakan bantuan program SPSS versi 23 yaitu dengan menggunakan uji normalitas, homogenitas, serta uji varian multivariat untuk melihat apakah terdapat pengaruh feedback dan kecerdasan intelektual (IQ) terhadap peningkatan penguasaan keterampilan pada cabang olahraga bolabasket.

\section{HASIL}

Penelitian ini berfokus pada proses pemberian treatment dengan cara mengamati video di dalam aplikasi android, kemudian siswa setelah mengamati video tersebut diharapkan dapat melakukan apa yang telah dilihat dari video. Dari data ini dapat dilihat bagaimana proses pemberian treatment apakah adanya pengaruh atau peningkatan terhadap penguasaan gerak pada teknik dasar bola basket.

Tabel 2. Kategori IQ Siswa yang mengikuti tes

\begin{tabular}{ccc}
\hline Kategori & Kelas Interval & N \\
\hline IQ Tinggi & $118-132$ & 15 \\
IQ Sedang & $104-117$ & 27 \\
IQ Rendah & $90-103$ & 30
\end{tabular}

Tabel 2 menjelaskan kategori IQ tinggi dengan rentang skor (118-132) terdapat 15 siswa.
IQ sedang dengan rentang skor (104-117) terdapat 27 siswa. Dan IQ rendah terdapat 30 siswa dengan rentang skor (90-103). Pengkategorian ini berdasarkan rata-rata dari hasil yang didapat dari siswa yang mengikuti tes.

Tabel 3. Pre-test dan Post-test Feedback

\begin{tabular}{cccc}
\hline & Pre-test & Post-test & Koefisien \\
\hline Kinematic & & & \\
Feedback & 50.57 & 68.21 & \\
Mean (SD) & $(6.31)$ & $(5.50)$ & .000 \\
Slow Motion & & & \\
Feedback & 43.36 & 65.80 & .000 \\
Mean (SD) & $(5.04)$ & $(5.95)$ & \\
$\quad$ IQ- & - & - & .154 \\
$\begin{array}{c}\text { Penguasaan } \\
\text { Gerak }\end{array}$ & & & \\
\hline
\end{tabular}

Tabel 3 menjelaskan kelompok kinematic dengan rata-rata pre-test 50,57 dan pada saat posttest menjadi 68,21, sedangkan kelompok slow motion dengan rata-rata pre-test 43.36 dan pada saat post-test menjadi 65.80 . Berdasarkan hasil pengujian didapatkan kesimpulan bahwa terdapat pengaruh yang signifikan antara pre-test dan post-test dengan arah postif sebesar 0,000 $(\mathrm{p}<0.05)$ atas pemberian perlakuan yang diberikan dari masing-masing kelompok antara kinematic feedback dan slow motion feedback. Hasil dari korelasi antara tes IQ dengan penguasaan gerak diperoleh informasi bahwa tidak terdapat hubungan dengan hasil sebesar 0,154 ( $\mathrm{p}>0.05)$.

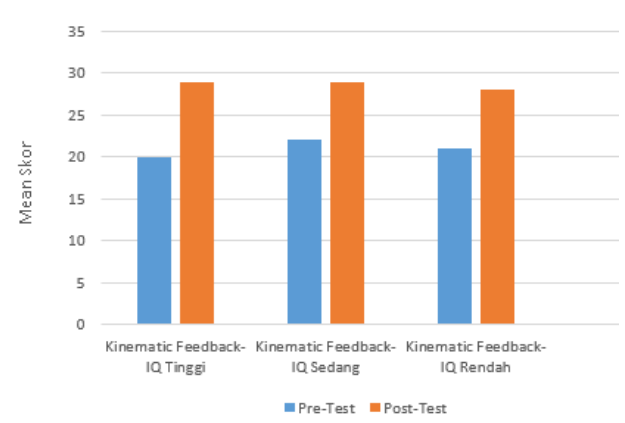

Gambar 1

Grafik Kelompok Kinematic 


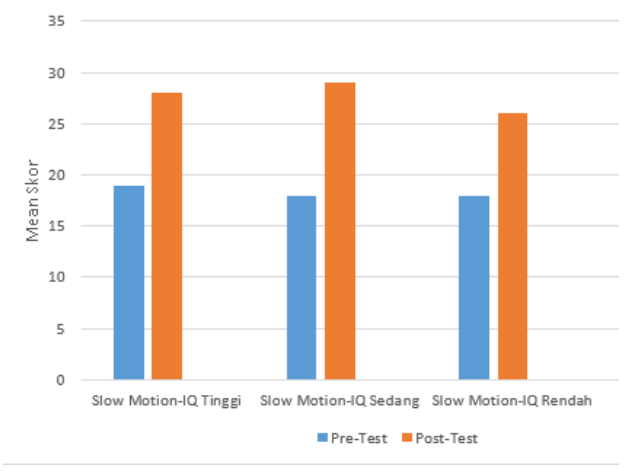

Gambar 2

Grafik Kelompok Slow Motion

Perbandingan antara pre-test dan post-test kelompok kinematic dan slow motion di masingmasing kategori menunjukkan perbedaan yang signifikan. Namun, perbandingan rata-rata antara kelompok kinematic tampaknya lebih besar dari rata-rata kelompok slow motion. Dapat diketahui bahwa umpan balik membantu para guru untuk menyadari tindakan mereka dalam mengajar (Viciana \& Salinas, 2008). Pada saat pemberian motorik dimana para siswa terlibat dalam aktivitas fisik. Ada tiga pilihan di dalamnya yaitu tes alternatif, tes berturut-turut dan tes simultan. Ketiga subkategori itu mari kita kendalikan jika seorang siswa melakukan aktivitas fisik sepanjang waktu ketika sebuah tes sedang dijalankan atau sedang digunakan dalam tes kita perlu membagi antara dua siswa antara eksekusi alternatif atau lebih dari dua eksekusi berurutan. Eksekusi simultan berarti semua siswa terlibat dalam aktivitas fisik selama tes.

\section{PEMBAHASAN}

Kontrol umpan balik digunakan untuk mendapatkan bimbingan bersama yang memaksakan kinematika yang diinginkan diperoleh dengan cara sistem penangkapan gerak, dan kemudian optimasi statis teknik menghitung eksitasi otot (Thelen DG). Pendekatan ini dapat menghasilkan gerak detail pada gerakan. Ketepatan perkiraan dan kegiatan visual belum dipelajari ulang bagaimana kegiatan tersebut dipengaruhi oleh kecepatan memutar video ulang yang berbeda diantaranya yaitu lambat, cepat dan normal. Gambar video lambat atau slow motion sekarang sedang banyak digunakan dalam pelatihan olahraga untuk mengevaluasi peserta didik (Casey \& Jones, 2011). Selanjutnya, skor tes kecerdasan pada usia 12 ditemukan memodifikasi asosiasi yang menyarankan individu dengan kecerdasan rendah di masa kecil mungkin mendapatkan manfaat terbesar dari pendidikan. Menurut penulis studi, penjelasan yang mungkin mengapa individu dengan kecerdasan rendah di masa kanak-kanak mendapat manfaat terbesar dari pendidikan.

Denmark merupakan sistem sekolah selama tujuh dekade terakhir terutama berfokus pada peningkatan membuktikan kemampuan yang paling tidak mampu. Oleh karena itu, studi masa depan diperlukan untuk menyelidiki apakah temuan penulis khusus untuk sistem sekolah Denmark atau apakah itu dapat digeneralisasi ke sistem sekolah di negara lain (Teasdale \& Owen, 1989). Konteks dalam olahraga, terkadang penilaian lebih dititik beratkan pada segi teknik saja. Dalam kenyataan IQ tinggi tidaklah menjamin kecerdasan seseorang.

Menurut Goleman tingkat kecerdasan hanya menyumbang $20 \%$ bagi kesuksesan, sedangkan $80 \%$ adalah sumbangan factor kekuatan-kekuatan yang lain. Kecerdasan intelektual menunjukkan siswa yang memiliki kategori tinggi tidaklah menjamin kecerdasan atau keberhasilan pada seseorang atau peserta didik dalam menerima materi pembelajaran dengan baik. Untuk meraih prestasi yang tinggi dalam belajar, seseorang harus memiliki tingkat kecerdasan yang tinggi, karena intelegensi merupakan bekal potensial yang akan memudahkan belajar dan pada gilirannya akan menghasilkan prestasi belajar yang optimal. Sehingga tes kecerdasan intelektual dianggap sebagai acuan penilaian kecerdasan seseorang. Oleh karenanya guru sebagai tenaga pendidik professional harus mengetahui dan memberikan materi dengan tepat pada siswa agar mereka dapat menyerap materi dengan baik. Indikator kesempurnaan pembelajaran pendidikan jasmani adalah kecakapan kognitif (pengetahuan), afektif (sikap), dan psikomotor (keterampilan gerak). Masing-masing memiliki peran penting dalam menunjang keberhasilan 
siswa untuk mencapai keberhasilan suatu pembelajaran.

Keberhasilan seseorang dalam melakukan suatu gerakan baik kognitif, lokomotor, nonlokomotor dan manipulative dalam suatu tujuan dengan efektif dan efisien. Keterampilan yang baik dari permainan bolabasket adalah keterampilan yang mampu menunjang permainan bola basket berjalan dengan baik. Dari hasil penelitian Jeroen Koekoek dkk menjelaskan bahwa proses berinovasi, memperkenalkan dan mengembangkan aplikasi digital yang dapat dikombinasikan dengan strategi didaktik game untuk mengajarkan kesadaran taktis dalam permainan olahraga. Pengembangan dan penggabungan keduanya menawarkan wawasan baru ke dalam waktu dan tempat yang tepat untuk menggunakan teknologi digital saat menggunakan teknologi untuk mengajarkan permainan olahraga. Selain itu, teknologi tersebut secara khusus untuk digunakan dalam konteks $P E$. Seperti halnya dengan banyak pilihan lain yang harus dibuat oleh guru relatif terhadap strategi pengajaran, setiap orang harus memutuskan apakah dibenarkan dan bermanfaat untuk menggunakan teknologi digital yang disajikan. Peneliti memberikan inovasi baru agar proses pembelajaran dapat berjalan dengan efesien dan efektif.

Tantangan dalam pendidikan jasmani adalah dengan menggunakan teknologi agar pembelajaran tersebut dalam cara yang berarti dan dapat meningkatkan pembelajaran siswa supaya tidak mudah bosan dan efektif. Peneliti juga memberikan umpan balik kepada siswa agar siswa dapat memahami apa yang telah disampaikan oleh guru. Dengan melalui pemberian umpan balik yang sesuai dengan perkembangan siswa maka siswa akan semakin memahami segala kelebihan dan kekurangan yang dimilikinya.

\section{KESIMPULAN}

Hasil saat ini menunjukkan bahwa pemberian perlakuan dapat mempengaruhi hasil belajar siswa yang signifikan, terutama dengan menggunakan teknologi yang modern akan menarik siswa menjadi lebih semangat dan tidak mudah bosan untuk mempelajari sebuah materi. Intelligent Quotient tidak bisa digunakan sebagai prediktor capaian prestasi siswa. Skor IQ tinggi maupun rendah tidak mempengaruhi perolehan hasil penguasaan gerak pada seseorang.. Guru dapat memilih untuk mendedikasikan waktu kelas untuk menyajikan modul tentang penggunaan teknologi digital dan proses penandaan yang ditujukan mendukung pengembangan game-play (Sinelnikov, 2012). Berdasarkan hasil dari pembahasan dalam penelitian ini, maka diajukan beberapa saran dengan harapan agar bermanfaat hasil dari penelitian ini. Bagi guru pendidikan jasmani, kesehatan dan olahraga (PJOK) agar aplikasi android dapat sebagai bahan masukan dan refrensi penggunaan media pembelajaran dalam pembelajaran PJOK. Bagi peneliti selanjutnya tidak menutup kemungkinan bila dikaji secara lebih luas dan mempertimbangkan penelitian ini dengan menghubungkan dengan variable lainnya, yang mempunyai kontribusi yang signifikan untuk mendapatkan hasil penelitian yang lebih baik.

\section{DAFTAR PUSTAKA}

Almada-Lobo, F. (2015). The industri 4.0 revolution and the future of manufacturing execution systems (MES). Journal of Innovation Management, 3(4), 16-21

Approved, U. G. C. (2017). Abhinav International Monthly Refereed Journal of Research in Management \& Technology EVOLVING WITH INTELLIGENCE QUOTIENT , EMOTIONAL INTELLIGENCE AND SPIRITUAL Abhinav International Monthly Refereed Journal of Research In. 6(6), 111-118.

Casey, A., \& Jones, B. (2011). Using digital technology to enhance student engagement in physical education. Asia-Pacific Journal of Health, Sport and Physical Education, 2(2), 51-66. https://doi.org/10.1080/18377122.2011.9 730351

Chaudhury, S., Garg, G., \& Sharma, P. K. (2003). Digital video revisited. IETE Technical Review (Institution of Electronics and Telecommunication Engineers, India), 20(4), 
309-318.

https://doi.org/10.1080/02564602.2003.1 1417088

Dalyono. 2004. Psikologi Pendidikan. Jakarta: Rineka Cipta.

Edwards, W. H. (n.d.). Motor Learning and Control From Theory to Practice.

Goleman, D. 2002. Kecerdasan Emosional : Mengapa IQ Lebih Tinggi Daripada EQ. Alih Bahasa : T. Hermaya. Jakarta : PT. Gramedia, ISBN : 9796054086

Juniu, S. (2011). Pedagogical uses of technology in physical education. Journal of Physical Education, Recreation \& Dance, 82(9), 41-49.

John McLester-Peter St.Pierre-. (n.d.).

Katsuhara Y., Fujii S., Kametani R., \& Oda S. (2010). Spatiotemporal characteristics of Rhythmic,stationary basketball bouncing in skilled and unskilled players. Perceptual and Motor skills. 110: 469-478

Koekoek, J., van der Mars, H., van der Kamp, J., Walinga, W., \& van Hilvoorde, I. (2018). Aligning Digital Video Technology with Game Pedagogy in Physical Education. Journal of Physical Education, Recreation and Dance, $\quad 89(1), \quad 12-22$. https://doi.org/10.1080/07303084.2017.1 390504

Lubay, L. H (2015). Pembelajaran Permainan Bolabasket. Bandung

Michael, D., \& Chen, S. (2006). Serious games:Games that educate, train, and inform. Stamford, CT: Thomson Course Technology PTR.

Mumtaz, S. (2000). Factors affecting teachers' use of information and communications technology: A review of the literature. Journal of Information Technology for Teacher Education, 9, 319-342.

Palao, J. M., Hastie, P. A., Cruz, P. G., \& Ortega, E. (2015). The impact of video technology on student performance in physical education. Technology, Pedagogy and Education, 24, 51-63.
Perbasi. (2012). Peraturan resmi bolabasket.[online]. Diakses: http://perbasi.or.id/peraturan-fiba/

Peter M McGinnis. (2013). Peter M.McGinnis 2013.Pot, N., Schenk, N., \& Van Hilvoorde, I. (2014). School sports and identity formation: Socialisation or selection? European Journal of Sport Science, 14, 484491.

Principles, F., Fifth, A., Richard, E., \& Timothy, A. S. (n.d.). Richard-A-Schmidt_-Timothy Donald-Lee-Motor-learning-and-performance-_from-principles-to-applicatio.

Pyle, B., \& Esslinger, K. (2014). Utilizing technology in physical education: Addressing the obstacles of integration. Delta Kappa Gamma Bulletin, 80, 35-39.

Siedentop, D., Hastie, P., \& van der Mars, H. (2011). Complete guide to sport education (2nd ed.). Champaign, IL: Human Kinetics.

Sinelnikov, O. A. (2012). Using the iPad in a sport education season. Journal of Physical Education, Recreation \& Dance, 83(1), 39-45. doi:10.1080/07303084.2012

Seth A, Pandy MG: A neuromusculoskeletal tracking method for estimating individualmuscle forces in humanmovement. J Biomech 2007, 40:356366.

Sony, M. (2018). Industry 4.0 and lean management: a proposed integration model and research propositions. Production and Manufacturing

Viciana, J., Fdez-revelles, A. B., Zabala, M., \& Requ, B. (2013). Computerized Application for Analysing the Time and Instructional Paranteters in Sport Coaching and Physical Education Teaching. (May 2014), 1-4.

Vermeulen, J., Luyten, K., Coninx, K., \& Marquardt, N. (n.d.). The Design of Slow Motion Feedback. (Figure 1). 
Tannehill, D., van der Mars, H., \& MacPhail, A. (2015). Building effective physical education programs. Sudbury, MA: Jones \& Bartlett.

Teasdale, T. W., \& Owen, D. R. (1989). Continuing secular increases in intellgence and a stable prevalence of high intelligence levels. Intelligence, 13(3), 255-262. https://doi.org/10.1016/01602896(89)90021-4.

Tearle, P., \& Golder, G. (2008). The use of ICT in the teaching and learning of physical education in compulsory education: How do we prepare the workforce of the future? European Journal of Teacher Education, 31, 55-72.

Thelen DG, Anderson FC, Delp SL: Generating dynamic simulations of movement using computedmuscle control. J Biomech 2003, 36:321-328.

Thelen DG, Anderson FC: Using computedmuscle control to generate forward dynamic simulations of human walking from experimental data. $J$ Biomech 2006, 39:1107-1115.Garn, A., \& Shen, B. (2015). Physical self-concept and basic psychological needs in exercise: Are there reciprocal effects? International Journal of Sport and Exercise Psychology, 13(2), 169-181. 